\title{
Design and Implementation of a Three-Phase Inverter Operated with different Conduction Modes with Automatic Powerfactor Improvement
}

\section{Mohammad Halimur Rahman, Mohammad Abdul Mannan and Mohd Muinul Haq Mamun}

\begin{abstract}
Three phase inverters are widely used to control different industrial process. Power electronics based inverters are very popular for fast response and precise control. In this paper an IGBT based three phase power inverter is proposed. Conventional three different conduction modes of $120^{\circ}, 150^{\circ}$ and $180^{\circ}$ have been adopted. Micro-controller based firing pulse generation circuit using a special multi-winding transformer and opt-coupler to apply isolated firing pulses for each IGBT has been developed and tested successfully. Simulation and test results of the inverter for three phase resistive as well as inductive loads have been presented. The test results are found to be in good agreement with the simulation outcome and also with the theoretical analysis. The main objective is to make an inverter with selectable conduction modes so that specific mode can be defined for resistive or reactive loads. The required correction for PFI is done by adjusting the percentage of duty cycle firing pulse of IGBT to control the capacitive current. The result of the experiment can be used to design PFI (Power Factor Improvement) units for the small industries and domestic users as well. In this paper a three phase inverter of multiple conduction mode with a switching capacitor power factor improvement (PFI) system is analyzed.
\end{abstract}

Keywords-Power Electronics, Phase controller, Converter, Inverter, Microcontroller, IGBT, Algorithm.

\section{INTRODUCTION}

An inverter circuit made it possible to convert DC power into $\mathrm{AC}$ power of required frequency and voltage. Uninterrupted power supplies, Variable frequency drive, High Voltage DC transmission Electric cars and various industrial application required $\mathrm{AC}$ power [1]. It is very important to have a steady output voltage and reduction in harmonics distortion by controlling power provided by the DC source and the inverter's gain. This gain of the inverter is determined by the ratio of the alternating power output to the direct power introduced to the inverter. By keeping the DC input voltage constant, output voltage can be change by varying the gain of the inverter while the DC voltage provided to the inverter is kept constant and the gain is increased it is possible to increase the output $\mathrm{AC}$ voltage of the inverter.

\section{Mohammad Halimur Rahman}

Dept. of Electrical and Electronic Engineering (EEE)

American International University Bangladesh.

Email: halim4751@gmail.com

Md. Abdul Mannan

Dept. of Electrical and Electronic Engineering (EEE)

American International University Bangladesh.

Email: mdmannan@aiub.edu

Mohd Muinul Haq Mamun

Dept. of Electrical and Electronic Engineering (EEE)

American International University Bangladesh.

Email: mamun297@yahoo.com

Recently different sine wave inverters [2], [3] and switching inverter is available, An IGBT based Inverter is illustrated and the firing pulses were created with an ATmega microcontroller. Three different conduction modes $\left(120^{\circ}, 150^{\circ}\right.$ and $180^{\circ}$ ) have been created in a single module. Depending on the type of load suitable modes can be selected to get higher efficiency and noise free operation in electric motors.

There are generally accepted few methods to improve the line power factor. Most popular methods are:

1. Synchronous condensers,

2. Static Capacitor, and

3. Phase advancers [2].

These methods are mostly used for large scale power factor improvement and are mainly used for sub-stations or industrial areas. But a good number of inductive loads are used in the rural areas and also in multi-stored buildings, where the users do not have the option to improve the power factor on the spot and thereby, reduce the load of the sub-station level PFI units. These users are also being deprived of the benefit of PFI as their electric meter has already counted the bill. If we can utilize the PFI at users' level, they can get the benefit of improved efficiency of most inductive load that are being used in common household application and common industrial motor loads.

\section{THREE PHASE INVERTER TECHNOLOGY}

The configuration for a Voltage Source Inverter is seen in Fig. 1. This configuration contains six switching devices, six diodes and 3 phase balanced load [4 - 7].

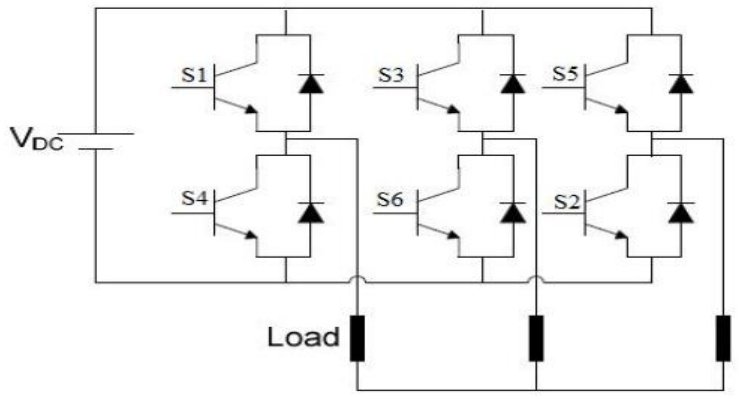

Fig. 1: Circuit Diagram of a three phase inverter

\section{PULSE SEQUENCE FOR THE INVERTER}

Sequence of the Switching devices will remain same for all the three different conduction modes only the time or the degree of conduction will vary [5].

\section{(a) $120^{\circ}$ conduction mode}

In this mode, two IGBTs are conducting at a time; the sequence is $12,23,34,45,56$ and 61 , as given in Table I. [8] [9]. 
TABLE I. CONDUCTION SWITCHES IN $120^{\circ}$ CONDUCTION MODE

\begin{tabular}{|c|l|l|l|l|l|l|l|l|}
\hline Iteration & Duration & \multicolumn{7}{|c|}{ Conducting Switches } \\
\hline 1 & $120^{\circ}$ & S1 & S2 & & & & & \\
\hline 2 & $120^{\circ}$ & & S2 & S3 & & & & \\
\hline 3 & $120^{\circ}$ & & & S3 & S4 & & & \\
\hline 4 & $120^{\circ}$ & & & & S4 & S5 & & \\
\hline 5 & $120^{\circ}$ & & & & & S5 & S6 & \\
\hline 6 & $120^{\circ}$ & & & & & & S6 & S1 \\
\hline
\end{tabular}

\section{(b) $150^{\circ}$ conduction mode}

The IGBT conduct in a sequence $123,23,234,34,345,45$, $456,56,561,61,612$ and 12 are given in TABLE II. So there are three modes of operation in one half cycles [8] [9] [10].

TABLE II. CONDUCTION SWITCHES IN $150^{\circ}$ CONDUCTION MODE

\begin{tabular}{|c|l|l|l|l|l|l|l|l|l|}
\hline Iteration & Duration & \multicolumn{7}{|c|}{ Conducting Switches } \\
\hline 1 & $150^{\circ}$ & S1 & S2 & S3 & & & & & \\
\hline 2 & $150^{\circ}$ & & S2 & S3 & & & & & \\
\hline 3 & $150^{\circ}$ & & S2 & S3 & S4 & & & & \\
\hline 4 & $150^{\circ}$ & & & S3 & S4 & & & & \\
\hline 5 & $150^{\circ}$ & & & S3 & S4 & S5 & & & \\
\hline 6 & $150^{\circ}$ & & & & S4 & S5 & & & \\
\hline 7 & $150^{\circ}$ & & & & S4 & S5 & S6 & & \\
\hline 8 & $150^{\circ}$ & & & & & S5 & S6 & & \\
\hline 9 & $150^{\circ}$ & & & & & S5 & S6 & S1 & \\
\hline 10 & $150^{\circ}$ & & & & & & S6 & S1 & \\
\hline 11 & $150^{\circ}$ & & & & & & S6 & S1 & S2 \\
\hline 12 & $150^{\circ}$ & & & & & & & S1 & S2 \\
\hline
\end{tabular}

\section{(c) $180^{\circ}$ conduction mode}

In $180^{\circ}$ Conduction mode at a time Three IGBT are conducting, conduction sequence is $123,234,345,456,561$, and 612 are given in TABLE III [8], [9].

TABLE III. CONDUCTION SWITCHES IN $180^{\circ}$ CONDUCTION MODE

\begin{tabular}{|c|l|l|l|l|l|l|l|l|l|}
\hline Iteration & Duration & \multicolumn{7}{|c|}{ Conducting Switches } \\
\hline 1 & $180^{\circ}$ & S1 & S2 & S3 & & & & & \\
\hline 2 & $180^{\circ}$ & & S2 & S3 & S4 & & & & \\
\hline 3 & $180^{\circ}$ & & & S3 & S4 & S5 & & & \\
\hline 4 & $180^{\circ}$ & & & & S4 & S5 & S6 & & \\
\hline 5 & $180^{\circ}$ & & & & & S5 & S6 & S1 & \\
\hline 6 & $180^{\circ}$ & & & & & & S6 & S1 & S2 \\
\hline
\end{tabular}

\section{PULSE GENERATION FLOWCHART}

Firing pulses have been created with different types of microcontroller and with different algorithm [9] [10] [11] [12]. The algorithm is used in this inverter design has been described and illustrated in Fig. 2.

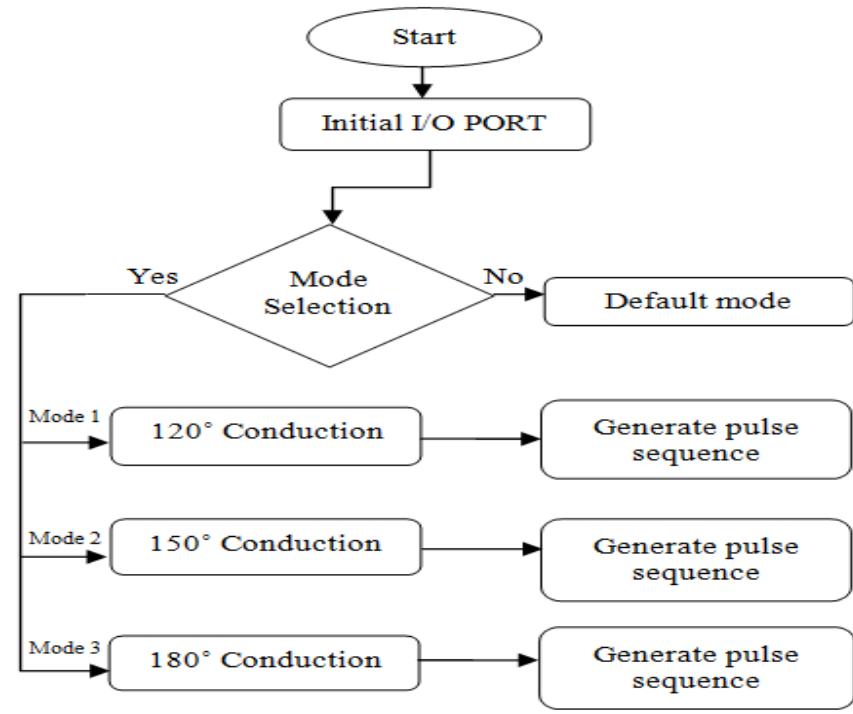

Fig. 2: Algorithm Used in the Pulse generator for IGBT
At the beginning all Input/output ports has been initialized. Then the program will continuously search for the mod selection pin to go high. Once it is high it will wait for 2 seconds and change the mode. $120^{\circ}$ has been kept as the default mode of operation. The mode sequence is $120^{\circ}, 150^{\circ}$ then $180^{\circ}$.The program will generate the pulse sequence predefined for each mode that is selected. The program will continue to execute the sequence until another mode is selected. The simulated circuit of inverter is shown in Fig. 3.

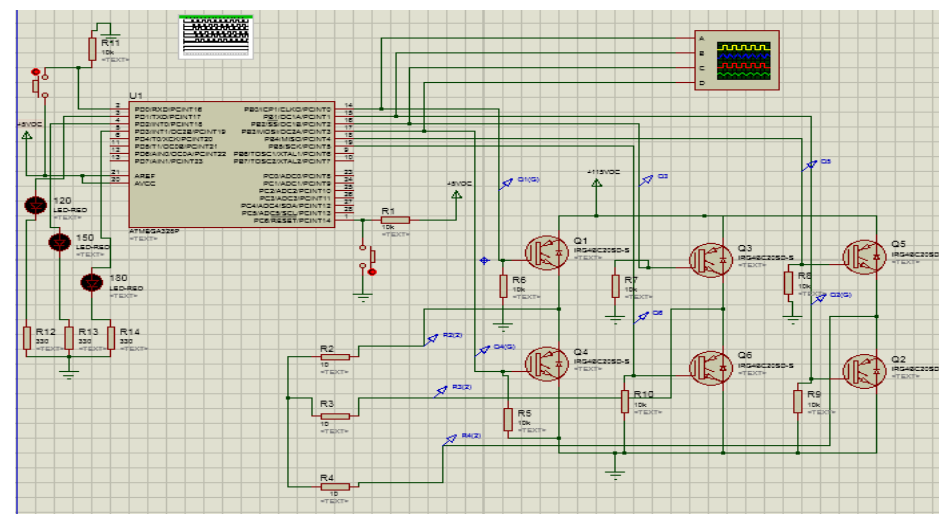

Fig. 3: Simulation Circuit Diagram of the inverter
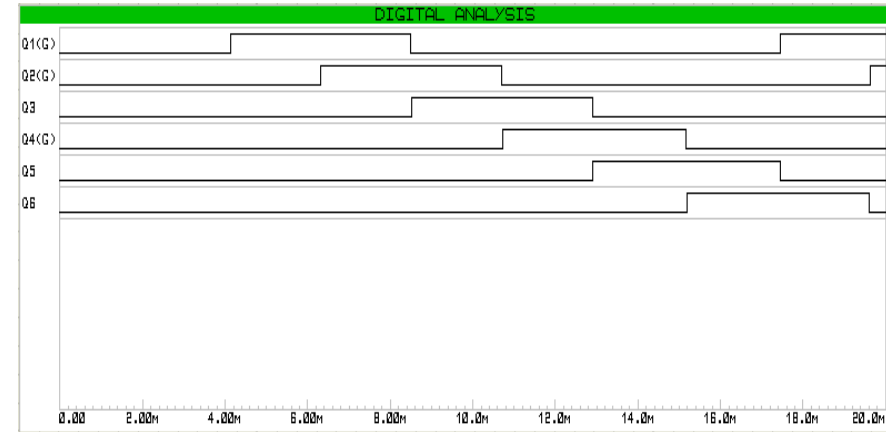

(a) Switching Pulse for $120^{\circ}$
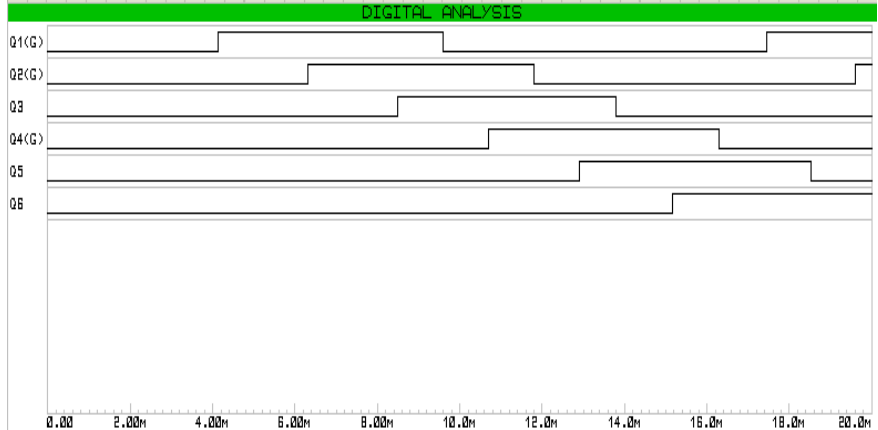

(b) Switching Pulse for $150^{\circ}$

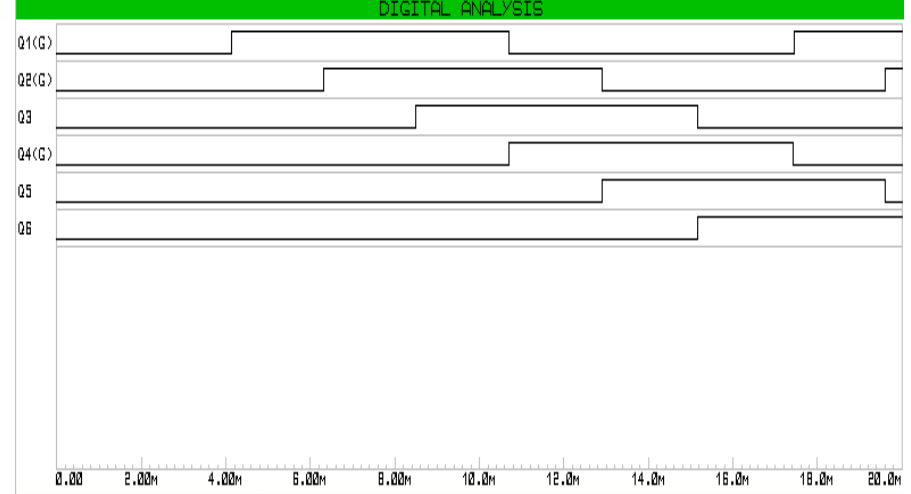

(c) Switching Pulse for $180^{\circ}$

Fig 4: Switching Pulse for different conduction modes. 
The algorithm used to generate the switching pulses has been shown in Fig. 2. The simulation was done with the help of Proteus software and the output pulses has been shown in Fig. 4.

\section{CIRCUIT IMPLEMENTATION AND RESUltS}

Firing pulse generation unit, IGBT Module and loads can be seen in Fig. 5.

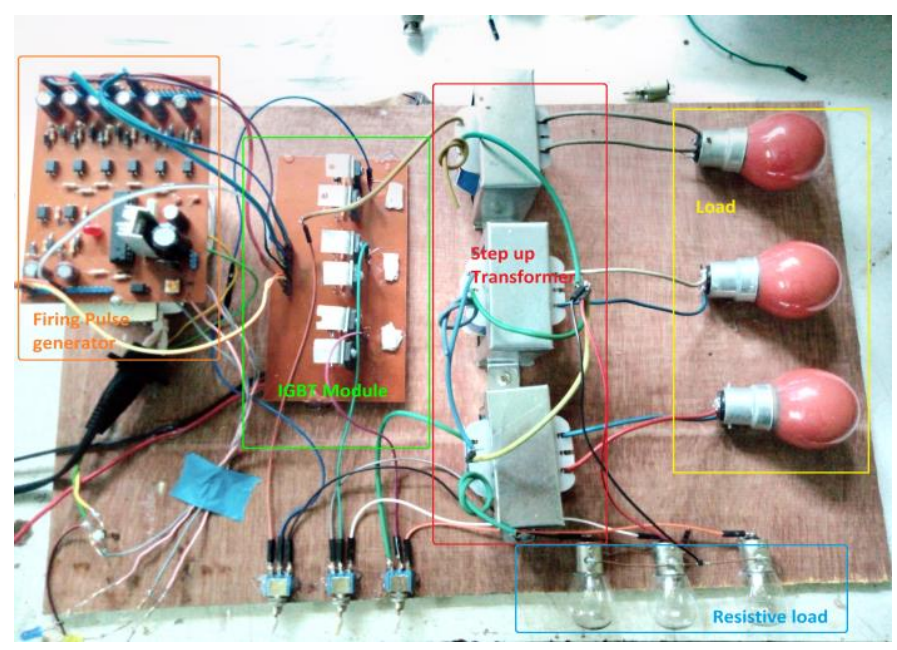

Fig. 5: Implemented inverter with various units.

\section{Output Voltages Wave shapes}

Output wave shape from the inverter with different modes has been justified with the simulation results [13]. Output wave shapes have been taken using Rigol DS1054Z Digital Oscilloscope have the Bandwidth of $50 \mathrm{MHz}$ and Number of Channel is 4, [14]. Figures 6 to 11 show the output voltage of implemented inverter for different loads with different conduction modes.

Fig. 6 and Fig. 7 show the line to neutral voltage from the implemented circuit for resistive load and induction mode with $120^{\circ}$ conduction mode.

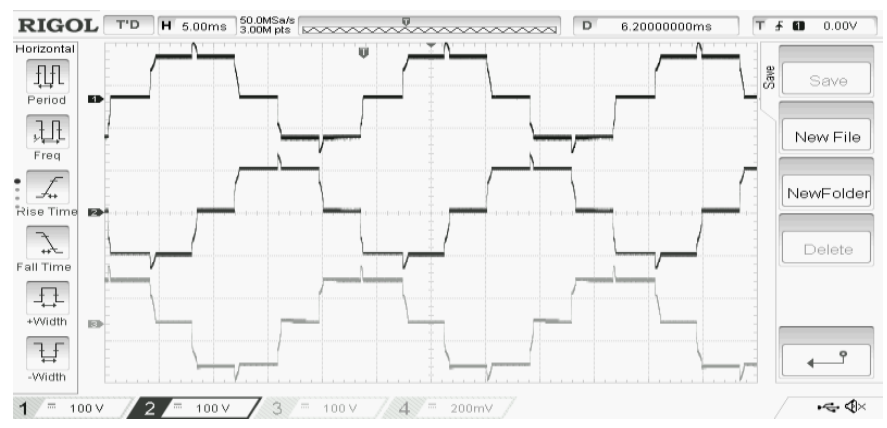

Fig. 6: Line to neutral voltage for resistive load for $120^{\circ}$ conduction mode.

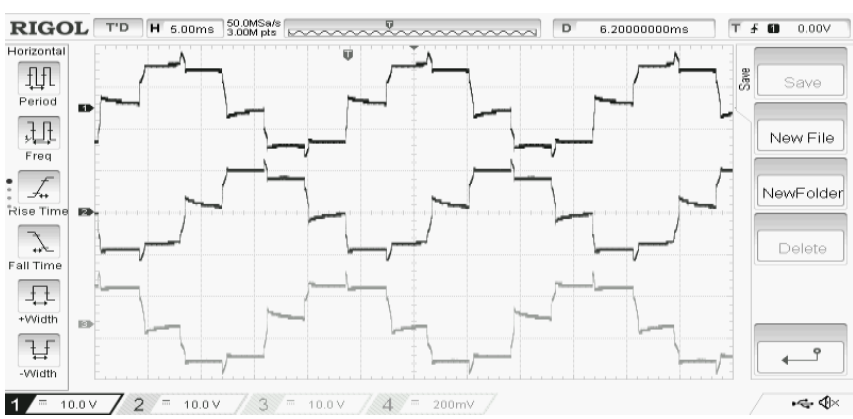

Fig. 7: Line to neutral voltage for inductive load for $120^{\circ}$ conduction mode.

Fig. 8 and Fig. 9 show the line to neutral voltage from the implemented circuit for resistive load and induction mode with $150^{\circ}$ conduction mode.

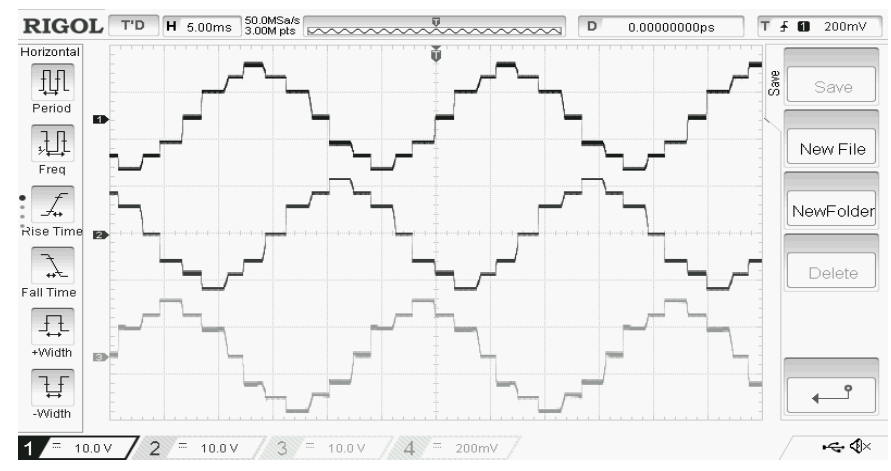

Fig. 8: Line to neutral voltage for resistive load for $150^{\circ}$ conduction mode.

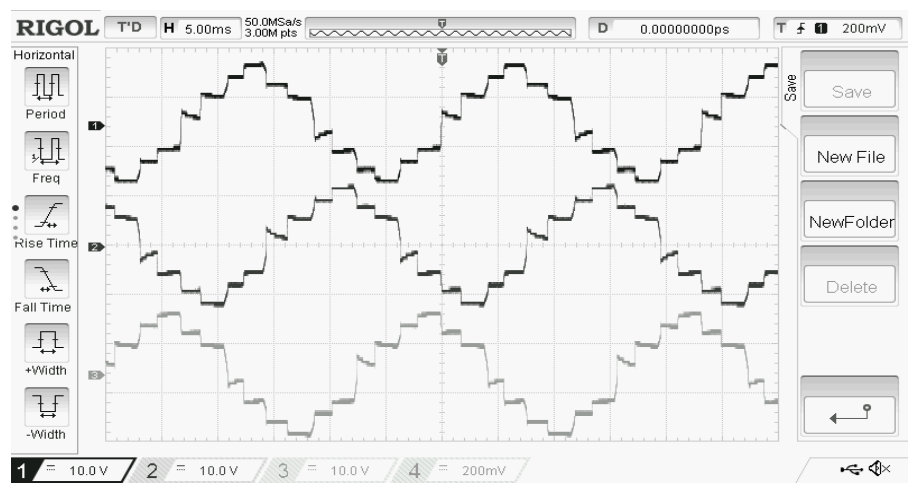

Fig. 9: Line to neutral voltage for inductive load for $150^{\circ}$ conduction mode.

Fig. 10 and Fig. 11 show the line to neutral voltage from the implemented circuit for resistive load and induction mode with $180^{\circ}$ conduction mode.

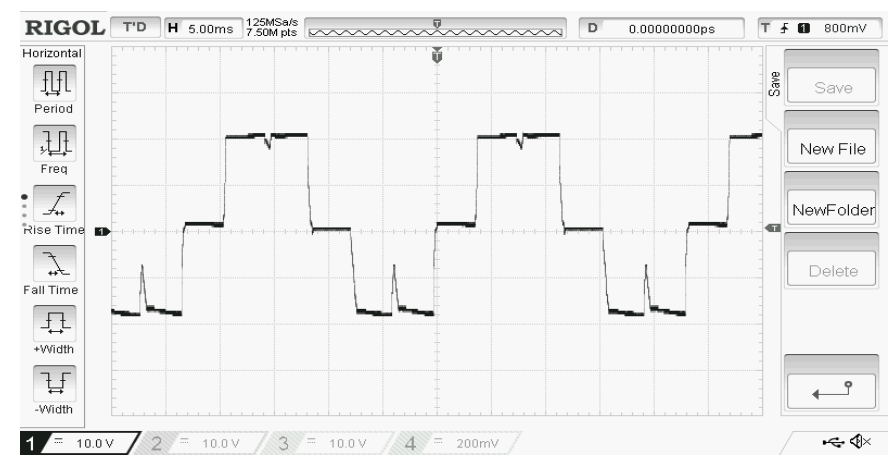

Fig. 10: Line to neutral voltage for resistive load for $180^{\circ}$ conduction mode.

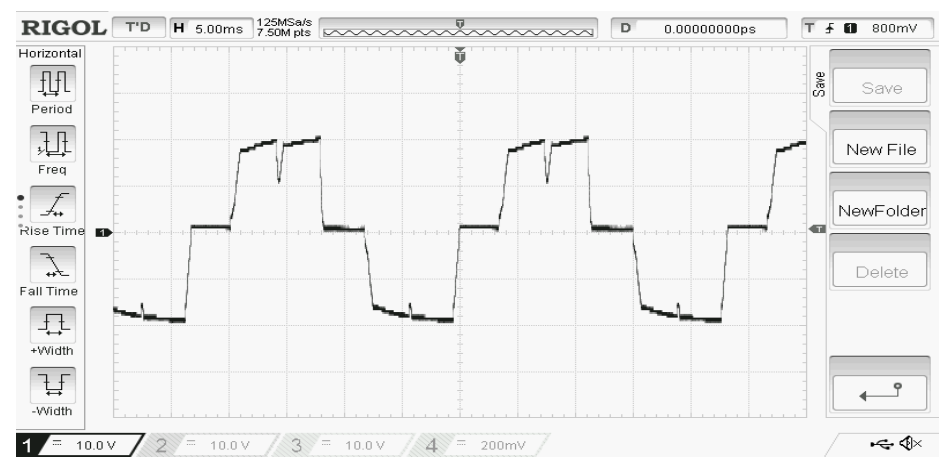

Fig. 11: Line to neutral voltage for inductive load for $180^{\circ}$ conduction mode.

\section{AUtOMATIC PFI By MicRO-CONTROLLER}

The practical experiment was found useful to achieve the power factor correction of a fixed load. But to achieve the unity power factor micro-controller is used. 
The algorithm is designed such that two different methods can be used to determine the power factor of the system. One is power factor calculation using time delay which is set as default method of determining the power factor at each full cycle of the sine wave. Another method is by determining the minimum value of the current. In this method lowest point of $\mathrm{V}$-curve is determined and the duty cycle is set such that microcontroller maintains this lowest point. At the lowest point power factor of the system is maximum.

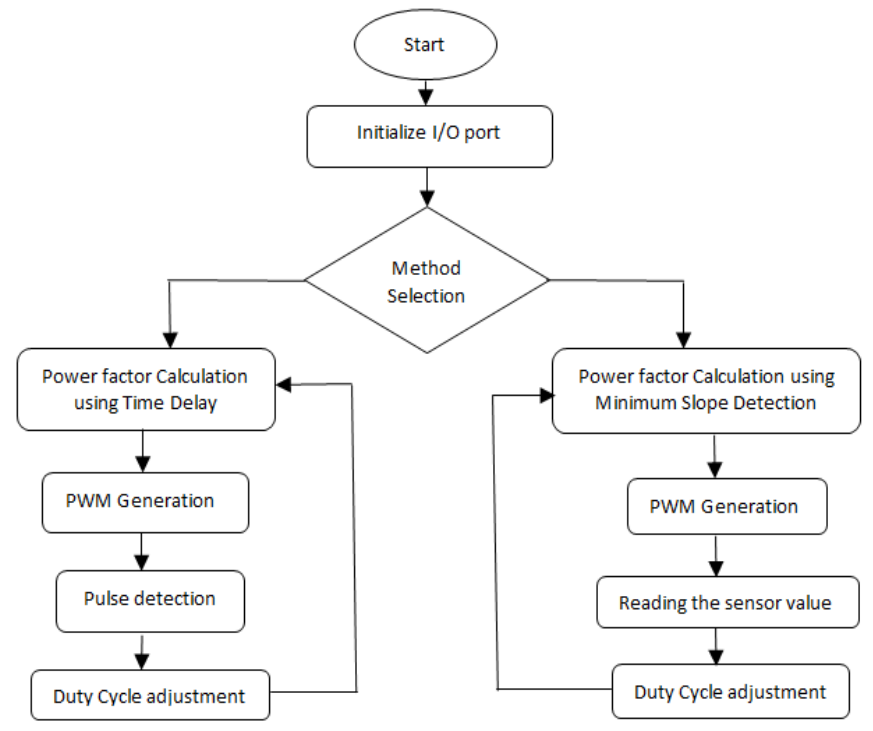

Fig13: Algorithm Used in the PFI system.

Minimum slope detection method works by measuring the total current, in this method microcontroller sets the duty cycle such that total current is always at its minimum value. From figure 3 it can be seen that when duty cycle is $41.44 \%$ or 0.4144 the value of current is $189 \mathrm{~mA}$ which is minimum amongst all the values of current for the load.

In second method microcontroller measures the power factor in every full cycle. For a $50 \mathrm{~Hz}$ line the microcontroller senses the current with a ACS712 current sensor and gets a pulse for every positive halfcycle and measures the time delay between current and voltage in every $20 \mathrm{~ms}$.

After measurement of the timedelay between the voltage and current, the time is converted into power factor.Table 2 shows different time delay and their corresponding power factor.

After the power factor is determined, microcontroller will set the duty cycle so that the power factor increases as close as possible to unity .

The gating signal generation was done using an algorithm programmed in microcontroller. Gating pulses were provided through an isolation circuit

\section{CONCLUSION}

After generating the firing pulses, output wave shapes from the inverter has been compared to theoretical wave shapes to verify the inverter is functional as expected. Different response for different conduction modes with resistive and inductive loads has been studied. $150^{\circ}$ conduction mode gives a better result in sense of the wave shape of the voltage generated by the inverter. This modes resembles a shape which is very similar to a sinusoidal waveform. Whereas waveform of the $120^{\circ}$ and $180^{\circ}$ have more likely to a square wave. $150^{\circ}$ has a voltage step of 12 and the determined level is 7 which can be seen in the output waveform from the oscilloscope and $150^{\circ}$ has less harmonic distortion compared to the other two modes. The circuit is designed so that Suitable mode can be selected for different types of loads to achieve higher efficiency and noise-less operation. Overall output power of the inverter is 1000 Watt, However to achieve this amount of power to be delivered high performance source is needed. Thus drawing high power reduces the efficiency of the inverter. At a constant power drawing of 30 Watt and the input power was 40 Watt. So $75 \%$ efficiency has been achieved. The paper proposed a system for power factor correction where only a capacitor is used for power factor correction. The simulation and practical experiment has proved the system to be effective in case of a fixed load e.g., rural pumps etc. The system is also proved to be effective in case of variable loads by using a microcontroller and IGBT.

\section{REFERENCES}

[1] Novák, Martin, et al. "Electric power splitter pulse rectifier control in a hybrid propulsion system." Power Electronics and Motion Control Conference (EPE/PEMC), 2010 14th International. IEEE, 2010.

[2] Qazalbash, A. Ali, et al. "Design and implementation of microcontroller based PWM technique for sine wave inverter." Power Engineering, Energy and Electrical Drives, 2009. POWERENG'09. International Conference on. IEEE, 2009.

[3] Hassaine, L., et al. "Asymmetric SPWM used in inverter grid connected." Revue des énergies renouvelables 10.3 (2007): 421-429.

[4] Rashid, Muhammad H., ed. Power electronics handbook. ButterworthHeinemann, 2017.

[5] Abdulsada, Abdullah S., Isam M. Abdulbaqi, and Ali H. Ahmed. "A study of feeding an unbalanced load from a four-leg 3-phase inverter using SVPWM technique." 2018 1st International Scientific Conference of Engineering Sciences-3rd Scientific Conference of Engineering Science (ISCES). IEEE, 2018

[6] Farhadi, Masoud, and Mehdi Abapour. "Three-Switch Three-Phase Inverter With Improved DC Voltage Utilization." IEEE Transactions on Industrial Electronics 66.1 (2019): 14-24.

[7] Savulak, Stephen, Ben Guo, and Shashank Krishnamurthy. "Three-phase inverter employing PCB embedded GaN FETs." Applied Power Electronics Conference and Exposition (APEC), 2018 IEEE. IEEE, 2018.

[8] Mangrolia, D. G., D. B. Karvat, and H. D. Patel. "Study and Simulation of Three Phase Voltage Source Inverter in Different Conduction Modes." The Indian Journal of Technical Education (2012).

[9] Babaei, Ebrahim, and Mehdi Mahaei. "Improving output voltage of the three phase six-switch inverters." TELKOMNIKA (Telecommunication Computing Electronics and Control) 9.3 (2011): 497-502.

[10] Saied, Mohamed H., et al. "On three-phase six-switches voltage source inverter: A $150^{\circ}$ conduction mode." Industrial Electronics, 2006 IEEE International Symposium on. Vol. 2. IEEE, 2006.

[11] Ghalib, Mohamed A., Yasser S. Abdalla, and R. M. Mostafa. "Design and Implementation of a Pure Sine Wave Single Phase Inverter for Photovoltaic Applications." AMERRICAN SOCIETY FOR ENGINEERING EDUCATION, ASEE (2014): 1-8

[12] Sangswang, Anawach, George Rost, and C. O. Nwankpa. "A Modular Simulink-based controlled three-phase switch mode inverter." Power Engineering Society Summer Meeting, 2000. IEEE. Vol. 4. IEEE, 2000.

[13] "Rigol DS1054Z Digital Oscilloscope'.[online] Available: https://www.tequipment.net/Rigol/DS1054Z/DigitalOscilloscopes//[Accessed:15-Sept-2018].

[14] Garg, Rahul K., Soumyadeep Ray, and Nitin Gupta. "Reactive power compensation and power factor improvement using fast active switching technique." Power Electronics, Intelligent Control and Energy Systems (ICPEICES), IEEE International Conference on. IEEE, 2016.

[15] Shyni, S. M., M. W. Abitha, and C. Bhuvaneswari. "Power factor improvement of compact fluorescent lightings with valley-fill circuit." Computation of Power, Energy Information and Commuincation (ICCPEIC), 2017 International Conference on. IEEE, 2017.

[16] Kisan, Raskar Shivaji, and Pragati N. Korde. "Power factor improvement of agriculture feeder by using capacitor banks." Advances in Electrical Technology for Green Energy (ICAETGT), 2017 International Conference on. IEEE, 2017.

[17] M. Morris Mano, Logic and Computer Design Fundamentals, $5^{\text {th }}$ ed., Pearson Education Limited 2014. 


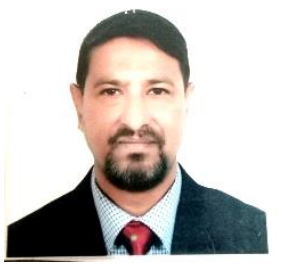

Mohammad Halimur Rahman

Received his Bachelor degree in

Electrical and Electronic

Engineering from Rajshahi

University of Engineering and

Technology (RUET former

BITR) in 1989. He joined in

Bangladesh Army in the Corps of Electrical \& Mechanical Engineering (EME) in 1993. His research interest includes circuit design, power electronics, nuclear power generation, smart grid and renewable energy sources.

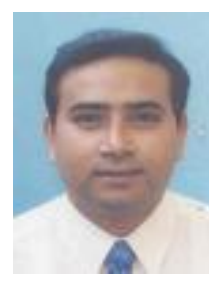

Mohammad Abdul Mannan Was born in Laxmipur, Bangladesh on January 01, 1975. He received his B. Sc. Eng.Degree from Rajshahi University of Engineering and technology (RUET former BITR), Bangladesh, in 1998, and Masters of

Engg and Dr. of Engg. Degrees from Kitami Institute of Technology, Japan, in 2003 and 2006 respectively, all in Electrical Engineering. He then joined in the American International University-Bangladesh (AIUB) as an Assistant professor. He is a member of the IEEE. His research interests include electric motor drive, power electronics, power system, wind generation system and control of electric motor, power electronic converters, power system and wind generation system. 